\title{
PRODUÇÃO DE ETILENO A PARTIR DO ETANOL COM USO DE DIFERENTES ALUMINAS COMERCIAIS COMO CATALISADORES
}

\author{
L. T. SILVA ${ }^{1}$, T. F. BRAGA ${ }^{1}$, F. S. FERRATO ${ }^{1}$, K. A. RESENDE $^{2}$ e S. C. DANTAS ${ }^{1}$ \\ ${ }^{1}$ Universidade Federal do Triângulo Mineiro, Departamento de Engenharia Química \\ ${ }^{2}$ Universidade Federal de Uberlândia, Faculdade de Engenharia Química \\ E-mail para contato: sandra@icte.uftm.edu.br
}

\begin{abstract}
RESUMO - O petróleo é a principal fonte para a obtenção de etileno, o qual dá origem ao polietileno. Visando minimizar o uso de combustíveis fósseis, ressurge na atualidade uma rota alternativa para a produção de etileno: a desidratação catalítica do etanol. Os catalisadores empregados nesta reação devem apresentar natureza ácida, o que está diretamente relacionado com a atividade catalítica. Dentre os mais utilizados, tem-se as aluminas. Neste trabalho, foram estudados: alumina comercial Catapal ${ }^{\circledR}$ com temperatura de calcinação de 700 e $900{ }^{\circ} \mathrm{C}$ e $\mathrm{CeZrO} 2 / \mathrm{Al}_{2} \mathrm{O}_{3}$ calcinada a $900{ }^{\circ} \mathrm{C}$. As amostras foram caracterizadas através de difração de raios $X(D R X)$ e análise textural de $N_{2}$. Foram realizados testes reacionais em temperaturas de 500 a $300{ }^{\circ} \mathrm{C}$. A análise de DRX mostrou que a estrutura dos catalisadores foi do tipo gama e theta-alumina. Com a análise textural de $\mathrm{N}_{2}$, notou-se que as amostras foram classificadas como mesoporosas e, para as amostras de alumina Catapal ${ }^{\circledR}$ puras, a temperatura de calcinação influenciou na área BET, mas não houve variação significativa do volume de poros, já para a mesma temperatura de calcinação, tanto a área específica quanto o volume de poros sofreram alteração com a adição de óxido misto de cériozircônio à amostra de Catapal ${ }^{\circledR}$ pura. Os testes reacionais mostraram que a conversão de etanol aumentou com o incremento da temperatura. Observou-se que maiores temperaturas favorecem a produção de etileno, enquanto as menos elevadas favorecem a de éter dietílico.
\end{abstract}

\section{INTRODUÇÃO}

Os combustíveis fósseis são, atualmente, as principais fontes de obtenção do etileno, cuja polimerização origina o polietileno, que é largamente aplicado industrialmente devido à sua não toxicidade e inércia face a diversos produtos químicos. Contudo, a busca por fontes alternativas de energia, fez ressurgir a reação de desidratação catalítica do etanol, que ficou estagnada por um período devido à atratividade econômica do uso de combustíveis fósseis como fonte para obtenção do etileno. O Brasil possui grande potencial para esta reação por ser um dos maiores produtores mundiais de cana-de-açúcar. O polímero resultante da polimerização do etileno oriundo do etanol é chamado de biopolímero, ou, ainda, "plástico verde". 
A escolha dos catalisadores é de fundamental importância para a reação, pois influenciarão, de acordo com De Lima (2010) na seletividade, conversão e formação de subprodutos. Os catalisadores empregados devem ser de natureza ácida, pois esta influenciará diretamente na atividade catalítica. Dentre os catalisadores mais empregados para a desidratação catalítica do etanol, tem-se a alumina, sílica e zeólitas. Segundo a literatura, a alumina é bastante empregada, pois permite elevadas conversões e seletividade para o etileno, além de ser de fácil obtenção e preparo.

Este trabalho de iniciação científica teve como objetivo estudar a produção de etileno a partir da desidratação catalítica do etanol, utilizando aluminas comerciais como catalisadores, calcinadas em diferentes temperaturas e sob condições reacionais distintas. Além disso, buscou-se avaliar a estrutura cristalina destes catalisadores, através da difração de raios $\mathrm{X}$ e análise textural de $\mathrm{N}_{2}$.

\section{METODOLOGIA}

Para este trabalho utilizou-se como catalisadores as aluminas comerciais: Catapal ${ }^{\circledR}$ calcinada à 700 e $900{ }^{\circ} \mathrm{C}$ e $\mathrm{CeZrO}_{2} / \mathrm{Al}_{2} \mathrm{O}_{3}$ calcinada a $900{ }^{\circ} \mathrm{C}$.

Para os testes reacionais, utilizou-se $10 \mathrm{mg}$ de catalisador e duas condições distintas de vazão de etanol: 0,150 e $0,300 \mathrm{~mL} / \mathrm{min}$. Além disso, variou-se a temperatura do reator de 500 à $300{ }^{\circ} \mathrm{C}$, com intervalos de $50{ }^{\circ} \mathrm{C}$. Os produtos reacionais foram analisados através de cromatografia gasosa.

A caracterização dos catalisadores se deu através da difração de raios $\mathrm{X}$ e análise textural de $\mathrm{N}_{2}$. A caracterização, assim como os testes catalíticos, foi realizada na Universidade Federal de Uberlândia.

\section{RESULTADOS}

Os dados obtidos através da difração de raios X são apresentados na Figura 1.

Figura 1: Difratogramas de raios $X$ dos catalisadores utilizados (a) Catapal ${ }^{\circledR} 900$ (b) Catapal@ 700 (c) $\mathrm{CeZrO}_{2} / \mathrm{Al}_{2} \mathrm{O}_{3} 900$

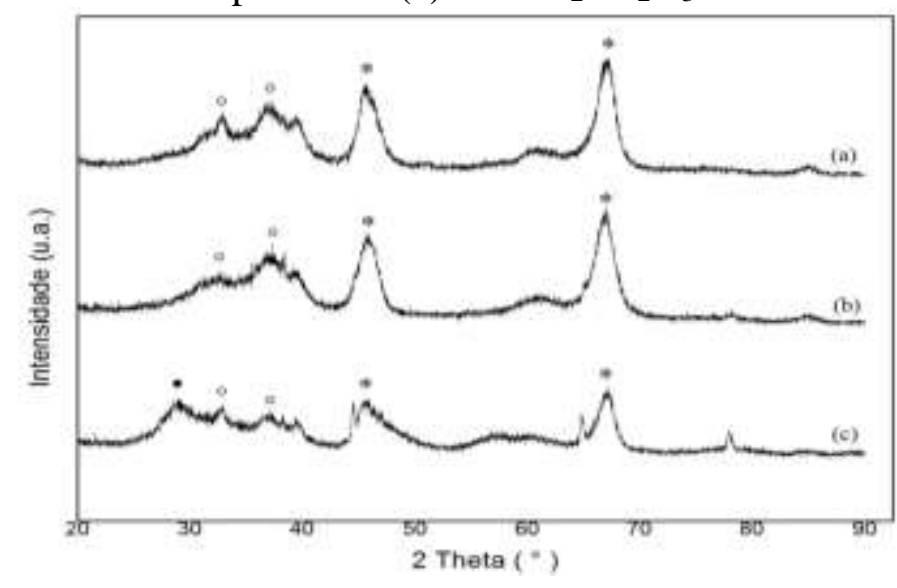

Fonte: (Das autoras) 
Silva (2007) afirma que os picos em $2 \theta=32,8^{\circ}, 36,67^{\circ}$ e $39,4^{\circ}$ indicam a fase $\theta$ alumina e picos em $2 \theta=28,6^{\circ}$ caracterizam a presença de cério, representados na Figura 1 por $(\circ)$ e $(\bullet)$, respectivamente. Logo, observou-se a presença de pequena quantidade de $\theta$-alumina nas amostras, pois apresentaram picos menos intensos. Para $\mathrm{CeZrO}_{2} / \mathrm{Al}_{2} \mathrm{O}_{3} 900$ notou-se a presença do pico característico do cério o qual não é observado nas demais amostras. Conforme De Lima (2010), os picos em, aproximadamente, $2 \theta=46^{\circ}$ e $67^{\circ}$, caracterizam a estrutura da $\gamma$-alumina, a qual está marcada na figura como $\left(^{*}\right)$, e estrutura cristalina tetragonal. Portanto, concluiu-se que as amostras utilizadas neste trabalho são referentes à $\gamma \mathrm{e}$ $\theta$-alumina,

Na Tabela 1 são apresentados os dados da análise textural de $\mathrm{N}_{2}$.

Tabela 1: resultados da análise textural de $\mathrm{N}_{2}$

\begin{tabular}{cccc}
\hline Amostra & Área BET $\left(\mathrm{m}^{2} / \mathrm{g}\right)$ & Volume de poros total $\left(\mathrm{cm}^{3} / \mathrm{g}\right)$ & $\mathrm{D}_{\mathrm{p}}(\AA)$ \\
\hline Catapal 900 & 145,924 & 0,432 & 115,408 \\
Catapal 700 & 161,049 & 0,462 & 102,547 \\
$\mathrm{CeZrO}_{2} / \mathrm{Al}_{2} \mathrm{O}_{3} 900$ & 138,876 & 0,338 & 103,857 \\
\hline
\end{tabular}

Fonte: (Das autoras)

Osmari (2015) afirma que o aumento da temperatura de calcinação reduz a área BET, o que provavelmente acontece devido à sinterização do cristal, que é o estreito contato das partículas em temperaturas suficientemente altas para produzir a união por coalescência, isto é, pela fusão de superfícies adjacentes. Contudo, o volume de poros não apresenta variação sistemática.

Ambas as amostras Catapal ${ }^{\circledR}$ pura mostraram comportamento de acordo com o que foi reportado por Osmari (2015). A adição de óxido de cério-zircônio à alumina Catapal® provocou a diminuição da área BET, conforme observado na literatura por Resende et al. (2009). Concluiu-se ainda que as amostras são do tipo mesoporosas, segundo a classificação de Bassane (2015), para a qual poros com diâmetros entre 20 e 500 Angstrons são denominados mesoporos.

A Figura 2 representa a conversão de etanol em função da temperatura nas diferentes condições estudadas neste trabalho. A Figura 2 evidenciou o aumento da conversão com a temperatura, o que era esperado, afinal, as velocidades das reações químicas são favorecidas por temperaturas mais elevadas. Observou-se, também, que maiores conversões foram obtidas para tempos de residência maiores, nos quais apresentam menor vazão de reagente e, consequentemente, maior contato deste com os sítios catalíticos.

Notou-se que a Catapal ${ }^{\circledR} 700$ e a Catapal ${ }^{\circledR} 900$ apresentaram, para ambas as condições reacionais, valores iguais de conversões, pois a diferença entre elas está dentro do erro experimental, que é de 5\%. As diferenças nas áreas específicas entre as amostras Catapal ${ }^{\circledR}$ pura não se mostraram como fator para diferenciar a conversão do etanol em nenhuma temperatura estudada. Logo, a temperatura de calcinação não influenciou no processo catalítico de desidratação do etanol, em relação à conversão. A adição do óxido de cério-zircônio à amostra de Catapal ${ }^{\circledR}$ provocou a diminuição da área BET, consequentemente, a diminuição da conversão na reação de desidratação catalítica do etanol.

Os valores de conversão obtidos para a reação na ausência de catalisadores foram significativamente menores do que os exibidos na Figura 2, sendo o maior deles de 6,190\%, para a temperatura de $500{ }^{\circ} \mathrm{C}$. Ressalta-se que a reação foi interrompida em $400{ }^{\circ} \mathrm{C}$ devido à conversão não significativa que fora obtida. Dessa forma, ficou evidente a necessidade do uso 
de catalisadores para esta reação. Além disso, concluiu-se que os catalisadores utilizados são apropriados, proporcionando conversões elevadas com apenas $10 \mathrm{mg}$.

Figura 2: Conversão de etanol em função da temperatura para os diferentes catalisadores: (a) Condição $1(0,150 \mathrm{~mL}$ etanol/min) (b) Condição $2(0,300 \mathrm{~mL}$ etanol/min)

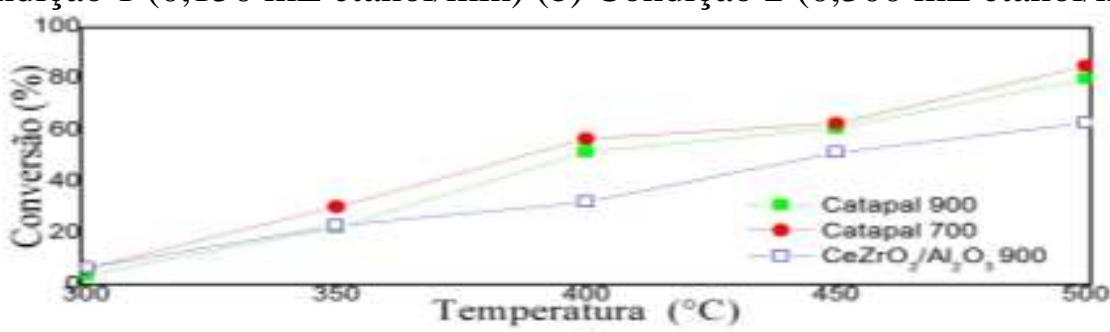

(a)



Fonte: (Autoras)

As Figuras 3 e 4 ilustram as seletividades para o etileno e o éter dietílico, respectivamente. Através da Figura 3, notou-se que a seletividade para o etileno foi crescente com a temperatura para todos os catalisadores estudados. Também foi possível observar que maiores seletividades foram obtidas para tempos de residência maiores, conforme retratado por De Lima (2010).

Na Figura 4, verificou-se que a seletividade do éter dietílico decresceu com o aumento da temperatura. Além disso, tempos de residência maiores diminuiram a seletividade deste produto, que segundo De Lima (2010), pode indicar a decomposição do éter dietílico em etileno nos maiores tempos de residência.

Analisando as Figuras 3 e 4 verificou-se diferentes porcentagens dos produtos reacionais para as diferentes temperaturas, indicando que, em temperaturas menores, a formação de éter-dietílico é favorecida, enquanto que, para temperaturas maiores a produção do etileno ocorre majoritariamente, em concordância com Phung e Busca (2015).

A produção de acetaldeído não foi significativa para nenhuma das amostras, sob nenhumas das condições reacionais, uma vez que o maior valor de seletividade observado para este produto foi de menos de 1\%. Isso reforça a afirmação de Phung e Busca (2015), de que acontecem apenas as reações de produção de etileno e éter-dietílico em competição. 
Figura 3: Seletividades para etileno:(a) Catapal ${ }^{\circledR} 900$ (b) Catapal ${ }^{\circledR} 700$ (c) $\mathrm{CeZrO}_{2} / \mathrm{Al}_{2} \mathrm{O}_{3} 900$

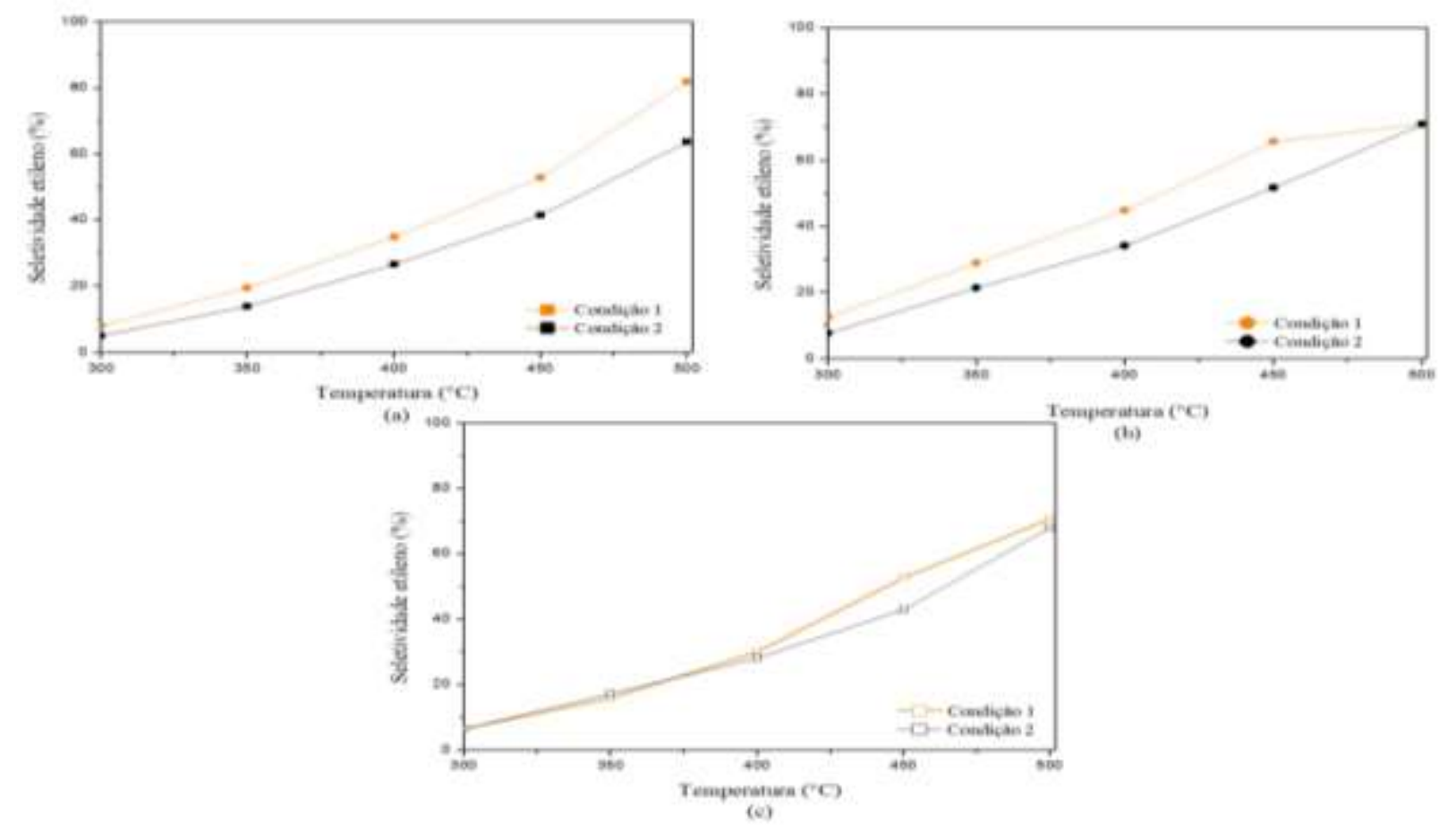

Fonte: (Das autoras)

Figura 4: Seletividades para éter dietílico: (a) Catapal® 900 (b) Catapal® 700 (c)

$\mathrm{CeZrO}_{2} / \mathrm{Al}_{2} \mathrm{O}_{3} 900$


Fonte: (Das autoras) 


\section{CONCLUSÃO}

Através da análise de DRX observou-se para todos os catalisadores a classificação do tipo $\gamma$ e $\theta$-alumina e, na amostra de $\mathrm{CeZrO} / \mathrm{Al}_{2} \mathrm{O}_{3}$ observou-se um pico relativo ao cério.

Os resultados da análise textural de $\mathrm{N}_{2}$ mostraram que maiores temperaturas de calcinação, para as amostras de alumina comercial pura, resultaram em área específica menor, enquanto o volume de poros não variou significativamente. A adição de óxido misto de cériozircônio à Catapal ${ }^{\circledR}$ provocou a diminuição da área BET e volume de poros. No que tange ao diâmetro dos poros, todas as amostras foram classificadas como mesoporosas. As amostras também foram classificadas como isotermas do tipo IV.

Nas duas condições reacionais utilizadas $(0,150 \mathrm{~mL}$ etanol/min e $0,300 \mathrm{~mL}$ etanol/min), observou-se que a conversão de etanol aumentou com o incremento da temperatura. Na condição com tempo de residência maior, obteve-se os maiores valores de conversão, em virtude da maior interação do reagente com os sítios catalíticos.

Já para a seletividade, maiores temperaturas favorecem a formação de etileno, enquanto para menores temperaturas a produção de éter-dietílico foi mais favorável. Além disso, para a formação do etileno, maior tempo de residência resultou em maior seletividade em comparação ao tempo de residência menor. Já para a produção de éter dietílico, o tempo de residência maior culminou na diminuição da sua seletividade. A formação de acetaldeído não foi significativa para nenhuma das condições estudadas, o que foi mostrado com menores seletividades em relação aos demais produtos.

\section{AGRADECIMENTOS}

Os autores agradecem à Fapemig (Projeto apq-02542-14) e pelo projeto de participação coletiva.

\section{REFERÊNCIAS}

BASSANE, B. C.; Síntese e caracterização de catalisadores de Co e Fe para a reação de Fischer-Tropsch. Pontifícia Universidade Católica (PUC), Rio de Janeiro, 2015.

DE LIMA, A. M. Estudo termodinâmico, cinético e otimização da produção de etileno a partir de etanol em alumina e óxido misto de cério-zircônio. Uberlândia, 2010. Dissertação (Pesquisa e Desenvolvimento de Processos Químicos). Universidade Federal de Uberlândia.

FLOOD, E. A. The Solid-Gas Interface, Marcel Ed. Dekker, V.1 Nova Iorque, 1967.

OSMARI, T. A. Cinética da reação de desidratação de etanol em alumina. Santa Maria, 2015. Dissertação (Engenharia de Processos). Universidade Federal de Santa Maria.

PHUNG, T. K., BUSCA, G. Diethyl ether cracking and ethanol dehydration: Acid catalysis and reaction paths. Genova, 2015, p. 92-101.

RESENDE, K. A.; SILVA, F. A.; NORONHA, F. B.; HORI, C. E. Catalisadores de platina para a oxidação parcial de metano. Universidade Federal de Uberlândia (UFU), 2009

SILVA, F. A. Estudo do efeito da dopagem da alumina com cério em catalisadores $\mathrm{Pt} / \mathrm{CeZrO} \mathrm{Z}_{2} / \mathrm{Al}_{2} \mathrm{O}_{3}$ na reação de oxidação parcial do metano. Uberlândia, 2007. Dissertação (Pesquisa e Desenvolvimento de Processos Químicos). Universidade Federal de Uberlândia. 